\title{
A Leaky Wave Antenna Design Based on Half-mode Substrate Integrated Waveguide Technology for X Band Applications
}

\author{
S. Doucha ${ }^{1}$, M. Abri ${ }^{2}$, H. Abri Badaoui ${ }^{3}$, B. Fellah ${ }^{4}$ \\ Telecommunication Departement, Faculty of Technology, University of Tlemcen- BP 230, Chetouane, \\ 13000 Tlemcen, Algeria
}

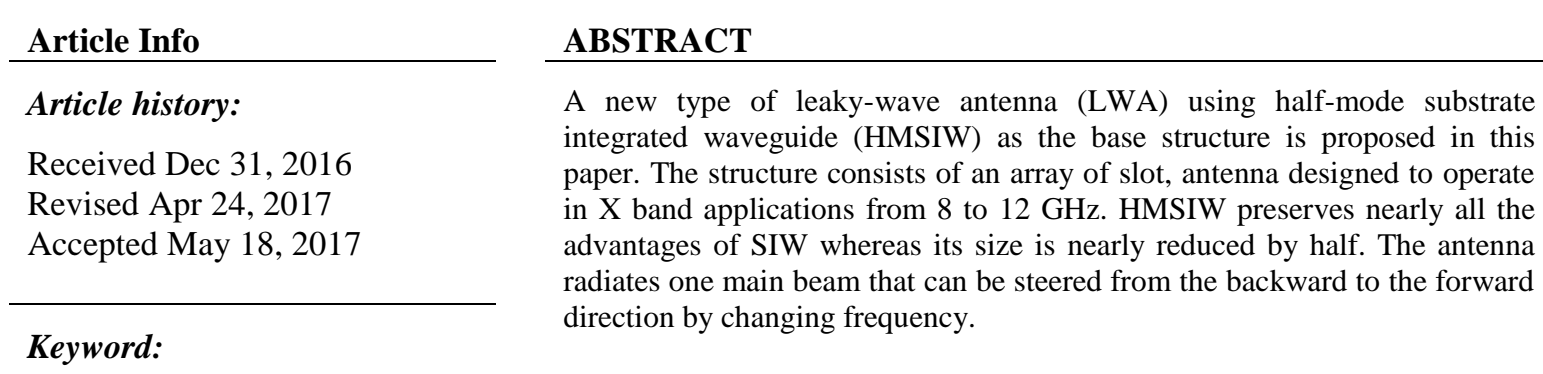

Leaky wave antenna

Half Mode substrate integrated

Waveguide

$\mathrm{X}$-Band

CST

Copyright () 2017 Institute of Advanced Engineering and Science. All rights reserved.

Corresponding Author:

\section{INTRODUCTION}

Substrate Integrated Waveguides (SIW) is used for transmission of Electromagnetic waves. They are planar structures belonging to the family of Substrate Integrated Circuits. Because of their planar nature, they can be fabricated on planar circuits like Printed Circuit Boards (PCB) and can be integrated with other planar transmission lines like microstrips. They retain the low loss property of their conventional metallic waveguides and are widely used as interconnection in high speed circuits, filters, directional couplers, antennas. The SIW consists of two linear metallic connected via dielectric substrate with a height of h. The electromagnetic fields within the SIW are confined by these metallic via arrays [1].

A more compact guided wave structure called half-mode substrate integrated waveguide (HMSIW) has recently been proposed [2],[3], which preserves nearly all the advantages of SIW whereas its size is nearly reduced by half. The transverse slotted rectangular waveguide is a simple structure that works as a leaky-wave antenna having frequency beam-scanning capability, with an orthogonal polarization from the conventional travelling-wave slotted antenna. Because of the polarization, the transverse slotted rectangular waveguide can scan from near broadside to end fire if the waveguide is filled with a dielectric material [4].

Due to their superior frequency-scanning capability and ease of feeding, leaky-wave antennas (LWAs) possess certain advantages over conventional antenna arrays. A high-gain LWA can be achieved by simply extending its physical length, which can result in a compact size especially in millimeter-wave applications. Furthermore, LWAs can be designed to exhibit both forward and backward beam steering by incorporating metamaterials into their unit cells [5],[6]. Nevertheless, the frequency-scanning capability of metamaterial-based LWAs is not suitable for more common fixed-frequency applications. Thus, there has been considerable interest in tunable scan angle LWAs [7]. 
In this paper, a novel leaky-wave antenna based on the HMSIW technique in the band $\mathrm{X}$ is presented, first we design a HMSIW component operating in X-band for TE10 mode with CST Microwave Studio ${ }^{\circledR}$ commercial software's. The design procedures begin by extracting the equivalent width guide and then calculate the width of HMSIW, by the following formulas design. After that, and for transit HMSIW to microstrip we use the ADS (advanced design system ) Software.

Finally, we design a leaky-wave antenna based on half mode substrate integrated waveguide (HMSIW) with transverse slots; the antenna radiates one main beam that can be steered from the backward to the forward direction by changing frequency. To confirm our results another simulator HFSS is used for comparison.

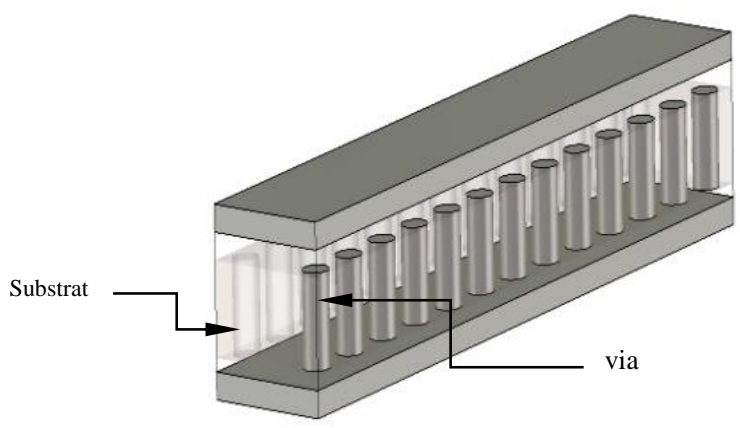

a) SIW

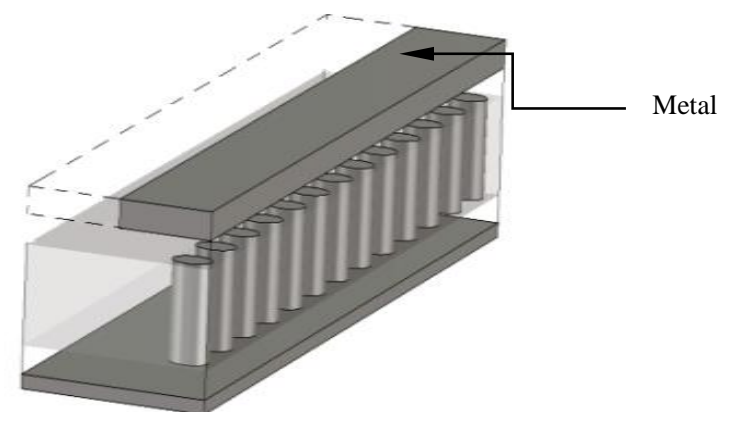

b) HMSIW

Figure 1. shows the construction of SIW and HMSIW

\section{HMSIW EQUATIONS}

When the dominant mode propagates in a SIW, the maximum value of E-field is placed at the vertical center plane along the transmission direction. In addition, because of large width to height ratio (WHR), the normal magnetic field is equal to zero at this plane. As a result, the symmetrical plane of SIW could be considered as a magnetic wall when it works at its dominant mode. Based on this theory, the SIW structure could be bisected into halves at the magnetic wall. Each half is called HMSIW and is able to support nearly half of the original field distribution. In this section we calculate the parameters of HMSIW by the following equations. Since SIW design generally works in TE1, 0 mode, so here $m=1, n=0$. Therefore the equation for cutoff frequency reduces to:

$$
f_{c}=\frac{c}{2 a}
$$

For DFW with same cut off frequency, dimension "ad" is found by:

$$
a_{d}=\frac{a}{\sqrt{\varepsilon_{r}}}
$$

Having determined the dimension ad for the DFW, we can now pass to the design equations for SIW [8].

$$
a_{s}=a_{d}+\left(\frac{d^{2}}{0.95 s}\right)
$$

where, $\mathrm{a}$ is the total broad side dimension of the rectangular waveguide, as is the separation between via rows (centre to centre), a is the width of DFW, $d$ is the diameter (as shown in Figure 2) and c is the velocity of light in free space. For SIW design, the following two conditions are required [9]:

$$
d \leq \frac{\lambda_{g}}{5}
$$




$$
s \leq 2 d
$$

where $: \lambda g$ (guided wavelength) is $[10]$

$$
\lambda_{g}=\frac{2 \pi}{\sqrt{\frac{(2 \pi f)^{2} \varepsilon_{r}}{c^{2}}-\left(\frac{\pi}{a}\right)^{2}}}
$$

\section{HMSIW DESIGN}

The Figure 2 shows the transmission coefficient and the reflection coefficient of HMSIW with different values of guide width $\left(a_{\mathrm{s} 2}\right)$, from the figure it can be seen that there is a transmission from the cutoff frequency (8.5GHZ) for a width equal to half of guide $\operatorname{SIW}\left(a_{\mathrm{s} 2}=a_{\mathrm{s}} / 2\right)$.
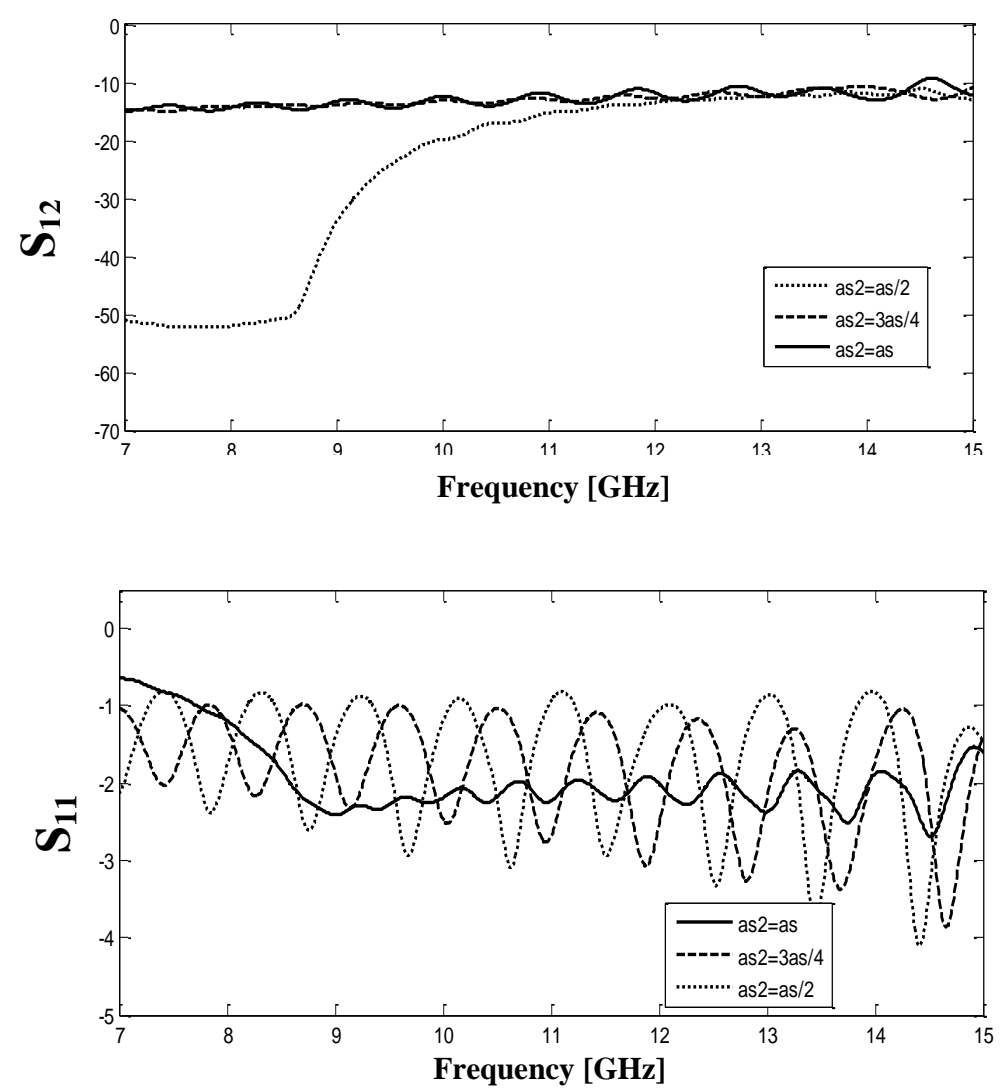

Figure 2. The transmission coefficient and the reflected power of the HMSIW waveguide for different values $a_{\mathrm{s} 2}$

The structure of the HMSIW is sketched in Figure 3. The substrate is covered with copper on both sides forming a waveguide, together with one row of metallic vias along the wave propagation direction, The thickness and the width of the HMSIW are $h$ and $a_{\mathrm{s} 2}$, respectively. The diameter of the metallic vias is d, and the period of the vias is s. We use The previous equations to build a HMSIW with CST by the following specifications; cutoff frequency of $\mathrm{TE}_{10}$ mode in SIW is selected about $8.5 \mathrm{GHz}$ with the following parameters : substrat type Arlon $\mathrm{Cu} 2331 \mathrm{x}$ (lossy), dielectric constant of $\varepsilon r=2.33$ and tang $\delta=0.0013$. The figure 4 shows the dominant mode electric fields of HMSIW guide simulated in frequency $10 \mathrm{GHz}$. 


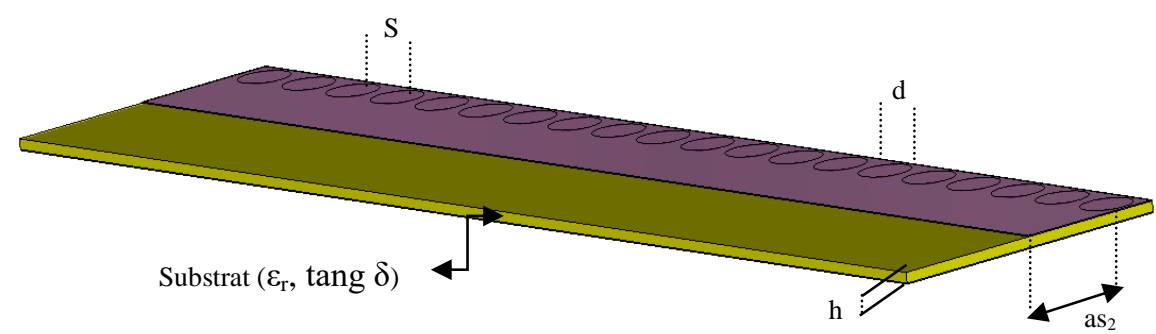

Figure 3. HMSIW parameters

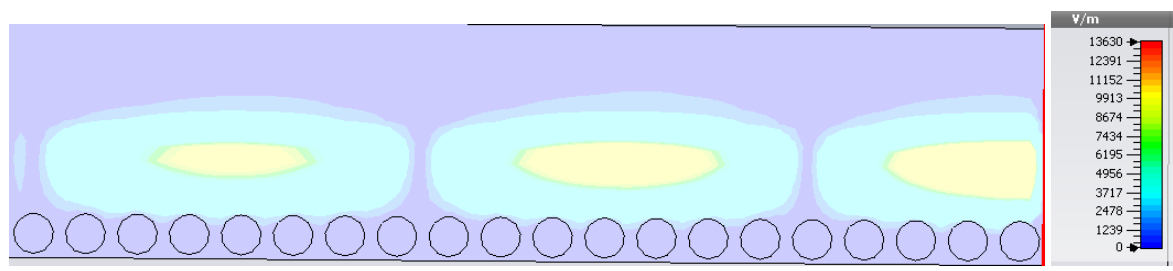

Figure 4. The dominant mode electric fields of HMSIW guide simulated in frequency $10 \mathrm{GHZ}$

The simulation results between the frequencies ranges [8-15 GHz] are illustrated in the figure 5, it is clear that the transmission between [7-8.5 GHz] is impossible because it is before the cutoff frequency, which is $8.5 \mathrm{GHz}$ as calculated theoretically. In this case, the transmission between [8.5-15 GHz] is low and this is due to the incorrect adaptation of the guide.

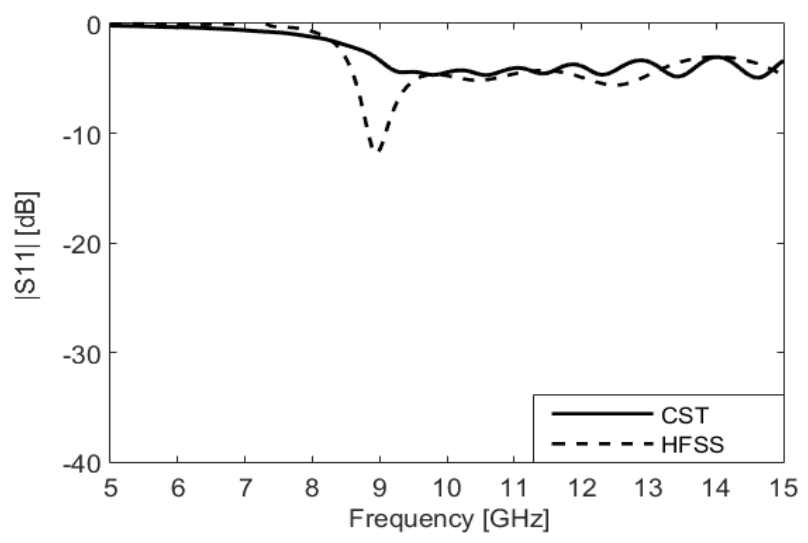

(a)

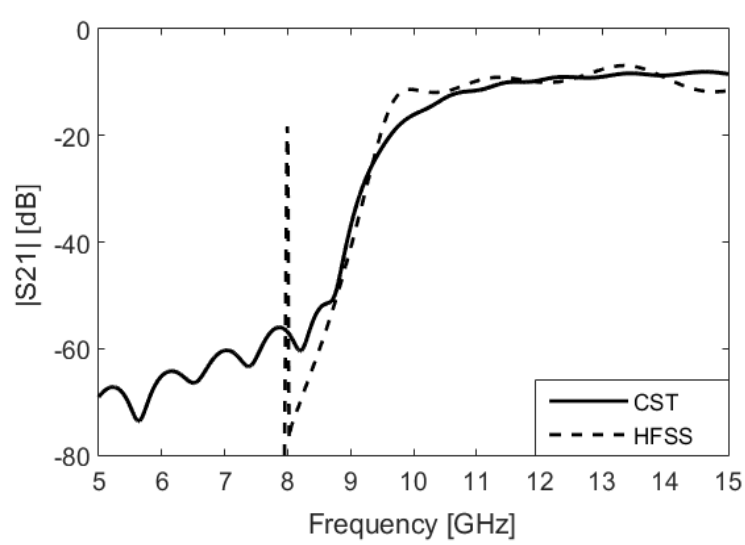

(b)

Figure 5. (a):The reflected power and (b) : the transmission coefficient of the HMSIW waveguide. The HMSIW waveguide parameters are set to: $a_{\mathrm{s} 2}=7.4 \mathrm{~mm}, d=2.5 \mathrm{~mm}, s=3.25 \mathrm{~mm}, h=0.508 \mathrm{~mm}$

Once the SIW is designed, it is necessary to have a transition to a transmission line to ensure a perfect adaptation. This transition contains two main parameters, the original width $\mathrm{W} 0$, the final width $\mathrm{W}$ of the profile line .It is necessary to calculate the impedance of SIW guide, which is given by the following formula [8] :

$$
\mathrm{Z}_{\mathrm{pi}}=\mathrm{Z}_{\mathrm{TE}} \frac{b \pi^{2}}{8 a_{s}}
$$


For the calculation of the guide impedance, it is also necessary to calculate the wave impedance of TE mode, which is given by [8] :

$$
\mathrm{Z}_{\mathrm{TE}}=\mathrm{j} \omega \frac{\mu}{\gamma}=\omega \frac{\mu^{\prime}}{\beta}=\sqrt{\frac{\mu}{\varepsilon}} \times \frac{\lambda \mathrm{g}}{\lambda}
$$

The calculated parameters are used to construct a taper by using ADS (advanced design system) software, the physical transition structure of microstrip line with the guide HMSIW is shown in Figure 6.

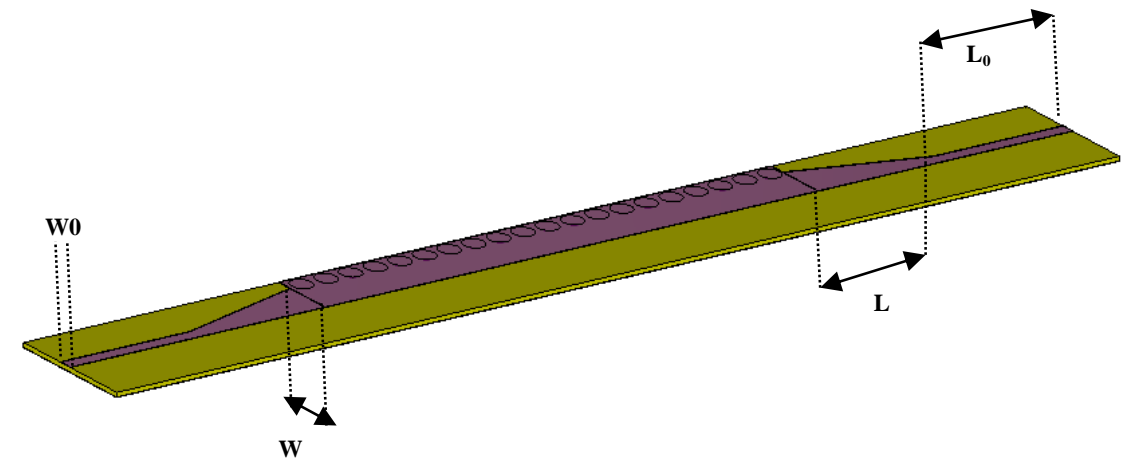

Figure 6. Topology of transition with HMSIW guide. with $\mathrm{w}=5.59 \mathrm{~mm}, \mathrm{w}_{0}=1.59 \mathrm{~mm}, \mathrm{~L}=16.63$ and $\mathrm{L}_{0}=16.99 \mathrm{~mm}$

The Reflected power and the transmission coefficient of the transition topology with HMSIW guide is obtained by simulation using CST software are shown in the Figure 7. One can observe that in the total passband $(8.5-15 \mathrm{GHz})$ the reflection coefficient $\mathrm{S} 11$ is less than $-10 \mathrm{~dB}$ and the $\mathrm{S} 12$ increases rapidly from the cut-off frequency to a total transmission of the power,obtained results are confirmed with HFSS which is used for comparison.

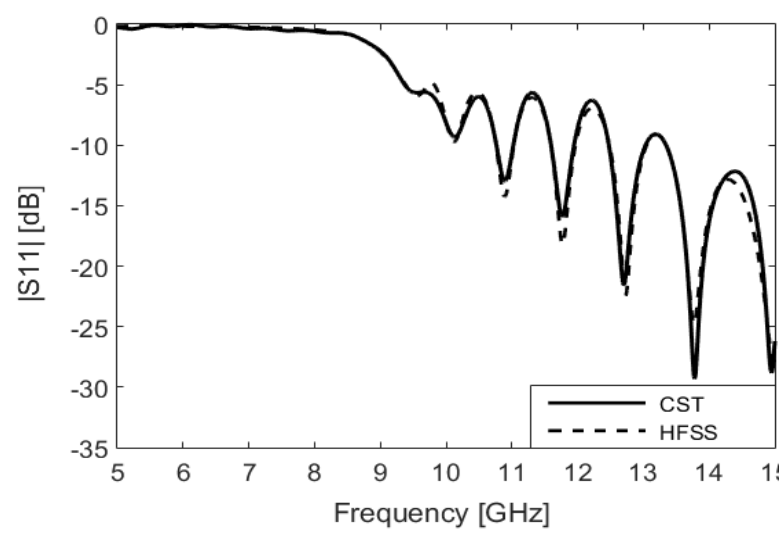

(a)

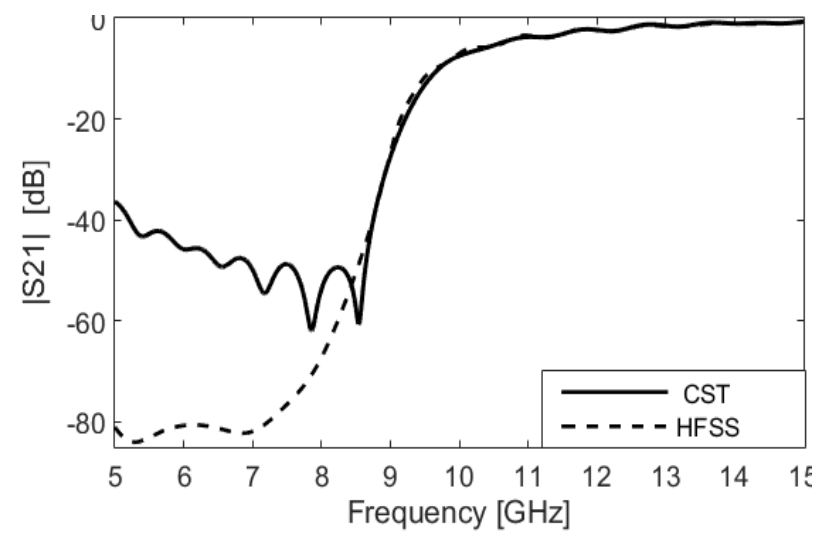

(b)

Figure 7. (a): Reflected power and (b): the transmission coefficient of the transition topology with HMSIW guide

\section{LWA BASED ON HMSIW DESIGN}

The leaky-wave antennas are essential to provide the benefit of high directivity without complex feeding network.The geometry of the HMSIW with transverse slot is shown in Figure 8. The leakage is obtained by the introduction of a periodic array of transverse slots on the top of HMSIW which interrupt the current flow on the top wall. The arrangement of the slots determines the polarization and the direction of radiation of the LWA antenna. The LWA antenna in HMSIW technology is designed on a substrate with a constant dielectric of 2.33 , tang $\delta=0.0013$ and thickness $0.508 \mathrm{~mm}$ for X-band applications. 


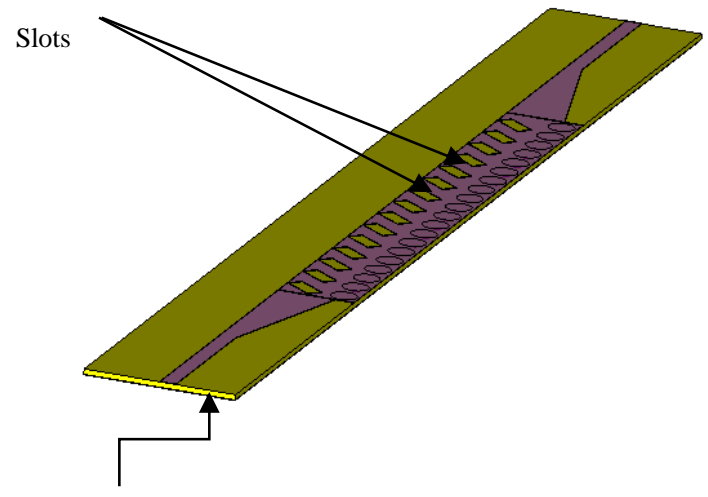

Substrat $\left(\varepsilon_{\mathrm{r}}, \operatorname{tang} \delta\right)$

(a)

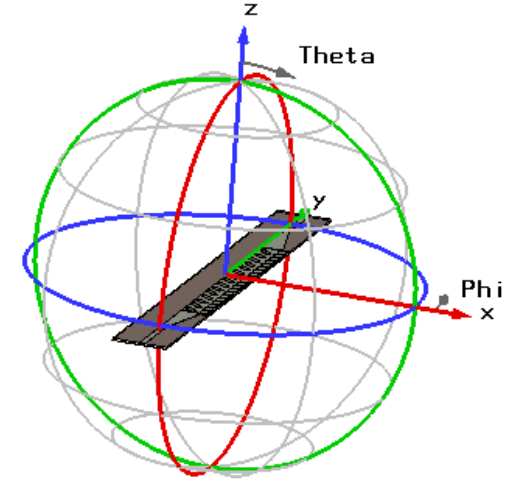

(b)

Figure 8. (a) Structure of leaky-wave antenna based on HMSIW, (b) LWA HMSIW alignment in the coordinates

The simulated results of S-parameters for leaky wave antenna based on HMSIW is shown in Figure 9. It can be observed that simulated $S_{11}$ is below $-10 \mathrm{~dB}$ from 8.5 to $15 \mathrm{GHz}$ and $S_{21}$ is bigger than $-5 \mathrm{~dB}$ from 9 to $15 \mathrm{GHz}$. The Figure 10 shows the dominant mode electric fields of LWA HMSIW simulated in frequency $10 \mathrm{GHz}$. The same results are also obtained with HFSS simulator.

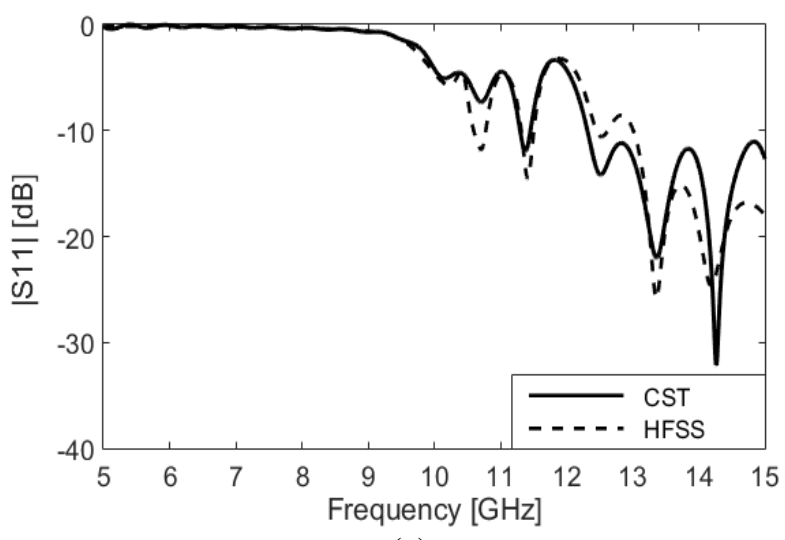

(a)

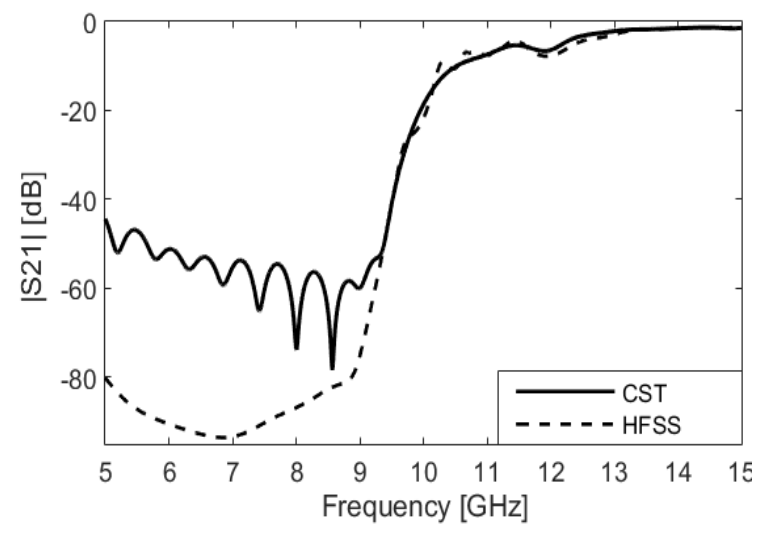

(b)

Figure 9.(a): Reflected power and (b): the transmission coefficient of LWA based on HMSIW

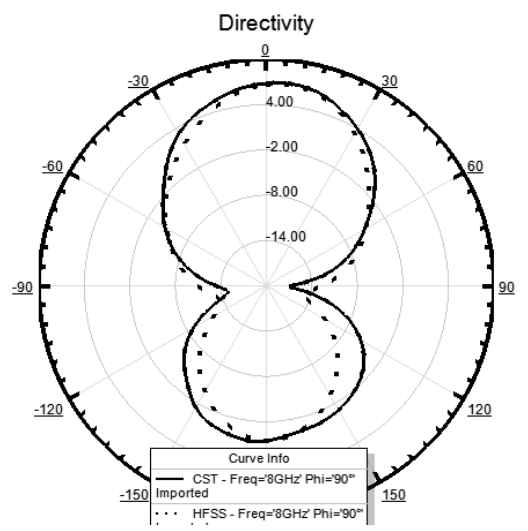

$\mathbf{f}=8 \mathbf{G H z}$

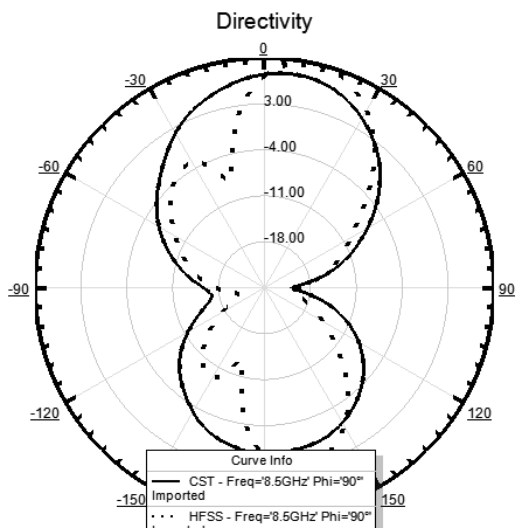

$\mathbf{f}=8.5 \mathrm{GHz}$ 

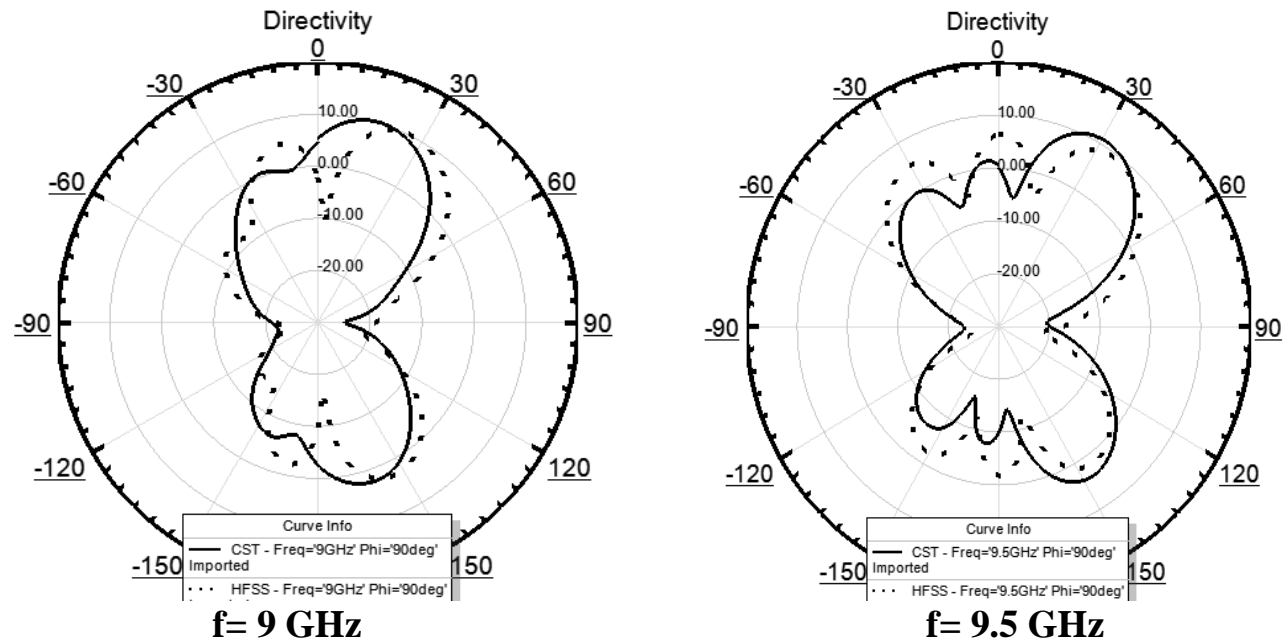

Figure 10. The simulated radiation patterns in polar coordinates

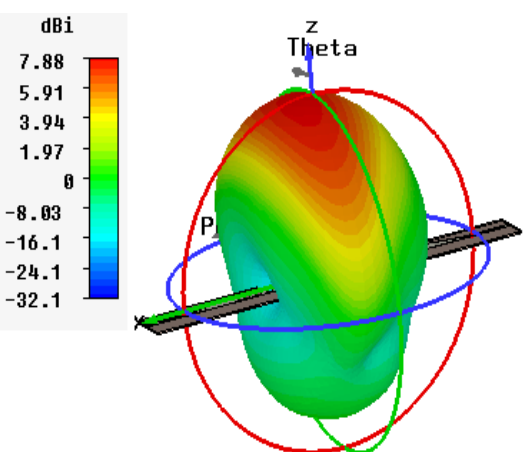

$\mathbf{f}=8 \mathrm{GHz}$

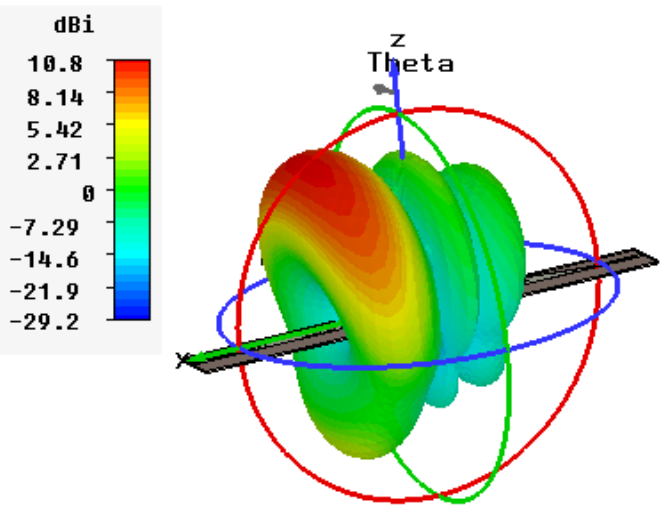

$\mathbf{f}=9 \mathbf{G H z}$
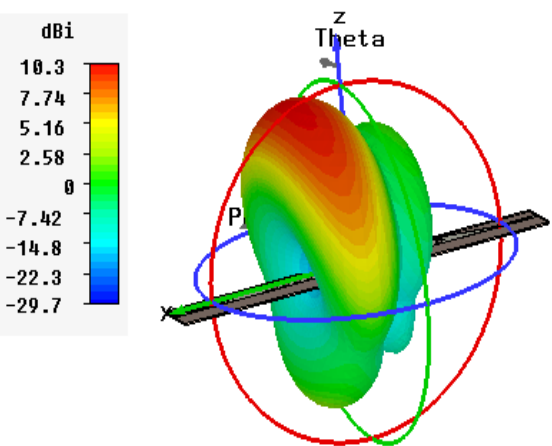

$\mathrm{f}=8.5 \mathrm{GHz}$
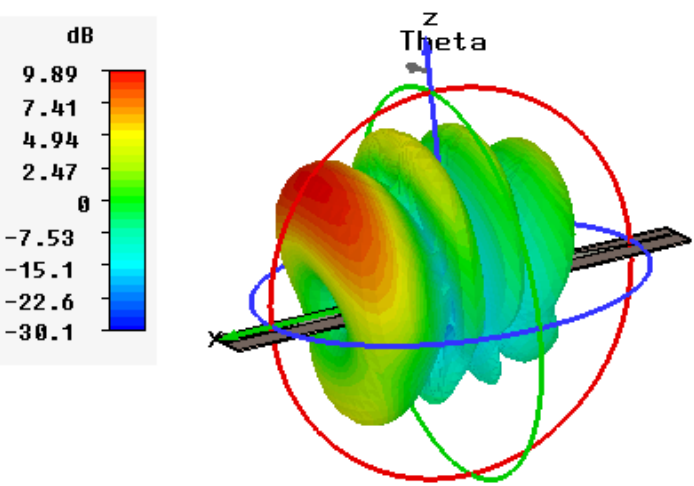

$\mathbf{f}=9.5 \mathrm{GHz}$

Figure 11. The simulated radiation patterns in 3-D

Figure 10 and 11 shows respectively the simulated radiation patterns in polar and 3-D. As shown, the mainlobe direction of this LWA HMSIW scans from $0 \circ$ at $8 \mathrm{GHz}$ to $46^{\circ}$ at $9.5 .5 \mathrm{GHz}$, with a maximal realized gain of $10.8 \mathrm{~dB}$ at $32^{\circ}(f=9 \mathrm{GHz})$. So when the frequency is increased, the narrow beam scans smoothly from the broadside to end fire direction. Both of HFSS and CST give the same result. 


\section{CONCLUSION}

A leaky-wave antenna based on the HMSIW technique is proposed. The antenna is characterized by many attractive advantages, including compact size, easy fabrication, low cost, low loss, wide bandwidth, and direct integration with planar circuits. The design is first passed by calculating the parameters of HMSIW, than we optimize the taper to make the transition between supply and input guide to ensure a perfect adaptation, after that we design a leaky wave antenna based on a half mode substrate integrated waveguide (HMSIW), simulations are realised with both of CST and HFSS ( for comparison ), the direction of radiation in this antenna change according to the variation of frequency.

\section{REFERENCES}

[1] A. Nasri, et al., "A Compact SIW Mixer for Millimeter-Wave Applications," International Journal of Electrical and Computer Engineering (IJECE), vol/issue: 4(6), pp. 902 908, 2014.

[2] Y. Q. Wang, et al., "Half mode substrate integrated waveguide (HMSIW) filter," IEEE Microw. Wireless Comput. Lett., vol/issue: 17(4), pp. 265-267, 2007.

[3] B. Liu, et al., "Half mode substrate.integrated waveguide (HMSIW) 3-dB coupler," IEEE Microw. Wireless Comput. Lett., vol/issue: 17(1), pp. 22-24, 2007.

[4] T. V. R. Krishna, et al., "Microstrip Line Fed Leaky Wave Antenna with Shorting Vias for Wideband Systems," International Journal of Electrical and Computer Engineering, vol/issue: 6(4), pp. 1725 1731, 2016.

[5] Y. Weitsch and T. Eibert, "A left-handed/right-handed leaky-wave antenna derived from slotted rectangular hollow waveguide," in European Microwave Conf., Munich, Germany, pp. 917-920, 2007.

[6] K. Okubo, et al., "New composite right/left-handed transmission line using substrate integrated waveguide and metal-patches," in IEEE MTT-S Int. Microwave Symp. Dig., Boston, MA, pp. 41-44, 2009.

[7] S. Lim, et al., "Electronically-controlled metamaterial based transmission line as a continuous-scanning leaky-wave antenna," in IEEE MTT-S Int. Microwave Symp. Dig., Fort Worth, TX, pp. 313-316, 2004.

[8] X. Chen, et al., "Substrate Integrated Waveguide (SIW) Linear Phase Filter," IEEE Microwave and Wireless Components Letters, vol/issue: 15(11), 2005.

[9] J. E. R. Sanchez and V. G. Ayala, "A General EM-Based Design Procedure for Single-Layer Substrate Integrated Waveguide Interconnects with Microstrip Transitions," IEEE MTT-S Int. Microwave Symp. Dig., Atlanta, GA, pp. 983-986, 2008.

[10] Y. J. Ban, “Tunable Ferrite Phase Shifters Using Substrate Integrated Waveguide Technique,” theses, 2010. 